\title{
Preparation of Novel T-type Polyurethanes with High Thermal Stability of Second Harmonic Generation and Their Nonlinear Optical Properties
}

\author{
Han-Na Jang, Ga-Young Lee, and Ju-Yeon Lee \\ Institute of Basic Science, Department of Chemistr: Inje University, Gimhae 621-749, Korea \\ E-mail: chemlivinjeackr \\ Received Februarv 11,2008
}

\begin{abstract}
2.5-Di-(2'-hyddroxyethoxy) benzy lidenemalononitrile (3) was prepared and polymerized with 2.4-toluenediisocyanate and 3.3'-dimethoxy-4.4'-biphenylenediisocyanate to yield novel T-type polyurethanes 4 and 5 containing 2.5-dioxybenzỵlidenemalononitrile. nonlinear optical (NLO)-chromophores as part of the polymer backbones. Polyurethanes $\mathbf{4}$ and $\mathbf{5}$ were soluble in common organic solvents such as acetone and N.Ndimethylformamide and showed a thermal stability up to $250^{\circ} \mathrm{C}$ with glass-transition temperatures $\left(T_{g}\right)$ in the range $119-1+6^{\circ} \mathrm{C}$. The second harmonic generation ( $\mathrm{SHG}$ ) coefficients ( $d_{32}$ ) of poled polymer films at 1064 nm fundamental wavelength were around $5.82 \times 10^{-5}$ esu. The dipole alignment exhibited high thennal stability up to $T_{g}$, and there was no SHG decay below $140^{\circ} \mathrm{C}$ due to the partial main-chain character of the polymer stnicture. which was acceptable for nonlinear optical device applications
\end{abstract}

Key Words : Nonlinear optics. Polyurethanes. Thermal stability, Second harmonic generation, Relaxation of dipole alignment

\section{Introduction}

Recently there has been an extensive research in the sy'nthesis of nonlinear optical (NLO) polymers because of their potential applications in the field of electro-optic devices. 1.2 Inorganic materials such as lithium niobate have many disadvantages such as slow response time and degradative photorefractive effects. which limit their applications. NLO polymers. on the other hand are considered candidate materials. mainly because they offer many advantages such as mechanical endurance. light weight chemical resistance. and good processability to fom optical devices. One of the current challenges is to design novel NLO polymers having optimized properties. In the developments of NLO polymers for electro-optic device applications. stabilization of electrically induced dipole alignment is an important consideration: in this context two approaches to minimize the randomization have been proposed namely the use of crosslinking ${ }^{3-6}$ and the utilization of high $T_{3}$ polymers such as polyimides. ${ }^{7.8}$ The polyurethane matrix forms extensive hydrogen bonding between urethane linkage and increases rigidity preventing the relaxation of induced dipoles. . $^{.10}$ Polyurethanes with a NLO chromophore. whose dipole moment is aligned transverse to the main chain backbone. showed a large second-order nonlinearity with good thermal stability. .1-12 Recently we reported novel Y-type NLO polyurethanes with enhanced thermal stability of second harmonic generation. ${ }^{13-17}$ In this work we have prepared novel T-ty'pe polyurethanes containing 2.5-dioxybenzy lidenemalononitrile group as a NLO-chromophore. We selected the latter because it has larger dipole moment than 2.5-dioxybenzylidenecyanoacetate group and is rather easy to synthesize. Furthermore, the 2.5-dioxybenzylidenemalononitrile groups constitute novel T-type NLO polyurthanes (see (a)

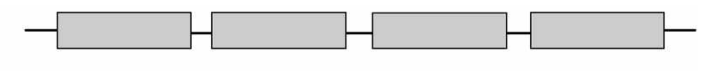

(b)

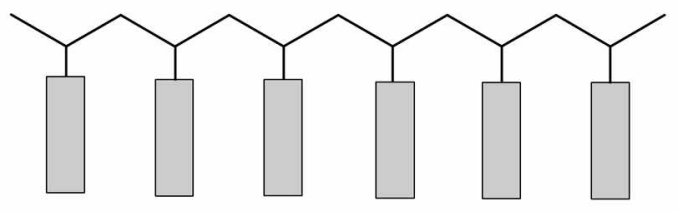

(c)

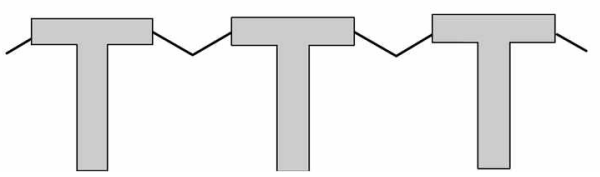

Figure 1. (a) Main-chain NLO polymers, (b) Side-chain NLO polymers, and (c) T-type NLO polymers.

Fig. 1c). and these T-type NLO polyurethanes have not been reported in the literature. Thus. we synthesized a new type of NLO polyurethane. in which the pendant NLO-chromophores are components of the polymer backbone. These mid-type NLO polymers are expected to have the advantages of both main-chain and side-chain NLO polymers namely stable dipole alignment and good solubility. After confirming the structure of the resulting polymers. we investigated their properties such as $T_{\mathrm{g}}$. thennal stability. surface morphology: and second harmonic generation (SHG) activity $\left(d_{33}\right)$.

\section{Results and Discussion}

Synthesis and Characterization of Polymers 4 and 5 . 2.5-Di-(2'-vinyloxyethoxy)benzaldehyde (1) was prepared by the reaction of 2-chloroethyl vinyl ether with 2.5dihy'droxybenaldehy'de. 2,5-Di-(2'-vinyloxyethoxy)benzyl- 
<smiles>C=COCCOc1ccc(OCCOCC(C)C)c(C=C(C#N)C#N)c1</smiles>

Scheme 1. Synthesis of diol 3.

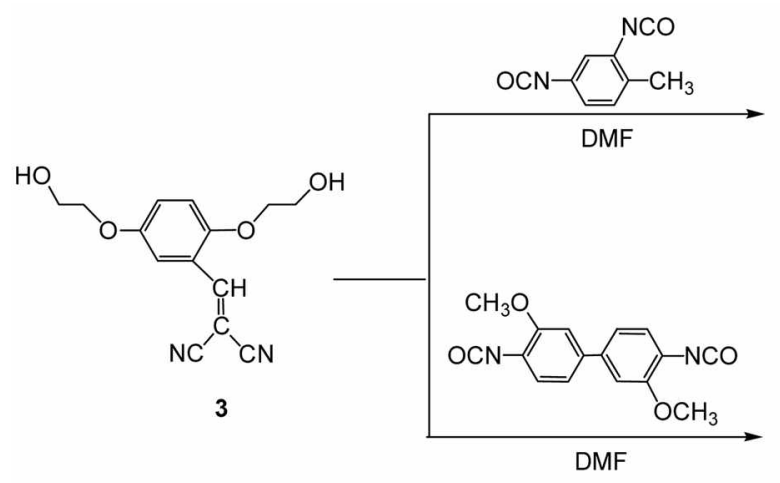

Scheme 2. Synthesis of polymers 4 and 5 .

idenemalononitrile (2) was prepared by the condensation reaction of compound 1 with malononitrile. Compound 2 was hydrolyzed to yield acetaldehyde and diol 3 . The synthetic route for compound 3 is presented in Scheme 1. Polymers 4 and 5 were prepared by the polyaddition reaction between a diol 3 and 2,4-toluenediisocyanate (TDI) and 3.3'dimethoxy-4.t'-biphenylenediisocyanate (DMBPI) in a dry DMF solvent (see Scheme 2). Polymerization results are sunumarized in Table 1. All polymerizations were carried out under stoichiometric conditions. We obtained polyurethanes with similar molecular weights and compositions. The polymerization yield was in the range $82-90 \%$. The structural feature of these polymers is that they have pendant NLO chromophores. which are parts of the polymer main chains. In this way the mid-type NLO polymers can have the advantages of both main-chain and side-chain NLO polymers simultaneously. The chemical structures of the compounds were identified by ${ }^{\mathrm{l}} \mathrm{H}$ NMR and IR spectra, and elemental analysis. All the analytical data confirmed the expected chemical structure. Elemental analysis results fit the polymer structures. 'H NMR spectra of the polymers showed a signal broadening due to polymerization, but the chemical shifts are consistent with the proposed polymer structures. The signal at 8.59-9.72 ppm assigned to the amine proton indicates the formation of urethane linkage. The IR spectrum of the same polymer sample also show a strong carbonyl peak near $1722 \mathrm{~cm}^{-1}$ indicating the presence of urethane bond. The number-average nolecular weights $\left(M_{\mathrm{n}}\right)$ of the polymer 4 was $16200\left(M_{\mathrm{w}} / M_{\mathrm{n}}=2.10\right)$. Polydispersities were in the range 1.90-2.12. Polymers + and 5 are soluble in common solvents such as acetone. DMF, and DMSO but are not soluble in methanol and diethỵl ether. The inherent<smiles>CCNC(=O)OCCOc1ccc(OCCOC(=O)Nc2ccc(C)c(C(F)(F)F)c2)c(C=C(C#N)C#N)c1</smiles><smiles></smiles>

viscosity values were $0.28-0.30 \mathrm{dL} \mathrm{g}^{-1}$. We now have well defined T-type polyurethanes, and investigated their properties in the following section.

Thermal Properties of the Polymers. The thermal behavior of the polymers was investigated by themogravimetric analy sis (TGA) and differential scanuing calorimeter (DSC) to determine the themal degradation pattem and $T_{\mathrm{g}}$. The results are summarized in Table 2. In Figure 2 and Figure 3. TGA and DSC thermograms of the polymers $t$ and $\mathbf{5}$ are presented. respectively. Polymers 4 and 5 showed a thermal stability up to $250^{\circ} \mathrm{C}$ according to their TGA thermograms. The initial weight loss in the polymers begins at $260-294^{\circ} \mathrm{C}$. Polymer 5 showed a higher initial degradation temperature than 4 . The $T_{g}$ values of the polymers 4 and 5 measured by $\mathrm{DSC}$ were 119 and $146^{\circ} \mathrm{C}$. respectively. Polymer 5 exhibited a higher $T_{g}$ value and can probably be attributed to the rigidity of the polymer backbone containing biphenyl group.

Film Morphology of the Polymers. To induce non-

Table 1. Polymerization ${ }^{a}$ of $3^{b}$ with $\mathrm{TDI}^{c}$ and $\mathrm{DMBPI}^{d}$ in DMF

\begin{tabular}{lcrrrrr}
\hline Monomer & $\begin{array}{c}\text { Monomer } \\
\text { Sovent } \\
\left(\mathrm{mol}^{-1}\right)\end{array}$ & $\begin{array}{c}\text { Time } \\
(\mathrm{h})\end{array}$ & $\begin{array}{c}\text { Yield } \\
(\%)\end{array}$ & $\begin{array}{c}\eta_{u+\mathrm{L}^{\circ}} \\
\left(\mathrm{dL} \mathrm{g}^{-1}\right)\end{array}$ & $M_{\mathrm{n}}{ }^{\prime}$ & $M_{\mathrm{w}}{ }^{\prime}$ \\
\hline 3, TDI & 0.40 & 8 & 90 & 0.28 & 14800 & 28600 \\
3, TDI & 0.80 & 10 & 92 & 0.30 & 16200 & 30800 \\
3, DMBPI & 0.40 & 8 & 86 & 0.28 & 13500 & 28600 \\
3, DMBPI & 0.80 & 10 & 88 & 0.29 & 14600 & 28200 \\
\hline
\end{tabular}

$\overline{{ }^{a} \text { All polynerizations were carried out under stoichiometric conditions. }{ }^{b} 3}$ $=2.5-\mathrm{Di}-(2$-hydroxyethoxy $)$ benzylidenemalononitile. ' $\mathrm{TDI}=2.4-$ Toluendiisocyanate. "DMBPI = 3.3"-Dimethoxy-4,4-biphenyenedisocyanate. "Inherent viscosity of polymer: Concentration of $0.5 \mathrm{~g} \mathrm{dL}^{-1}$ in DMSO at $25{ }^{\circ} \mathrm{C} .{ }^{/}$Measured by GPC in THF using polystyrene standard. 


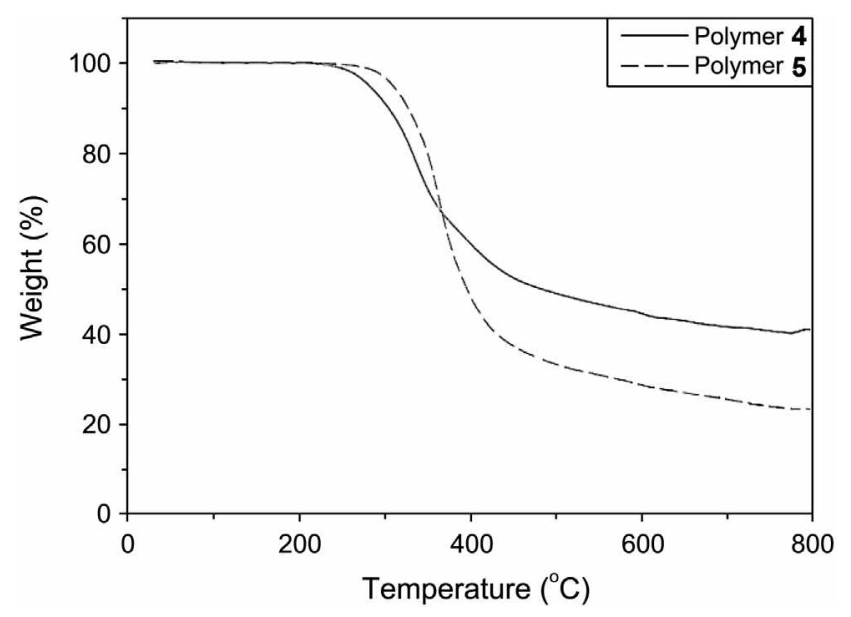

Figure 2. TGA themograms of polymers 4 and 5 at a heating rate of $10^{\circ} \mathrm{C} / \mathrm{min}$ under nitrogen.

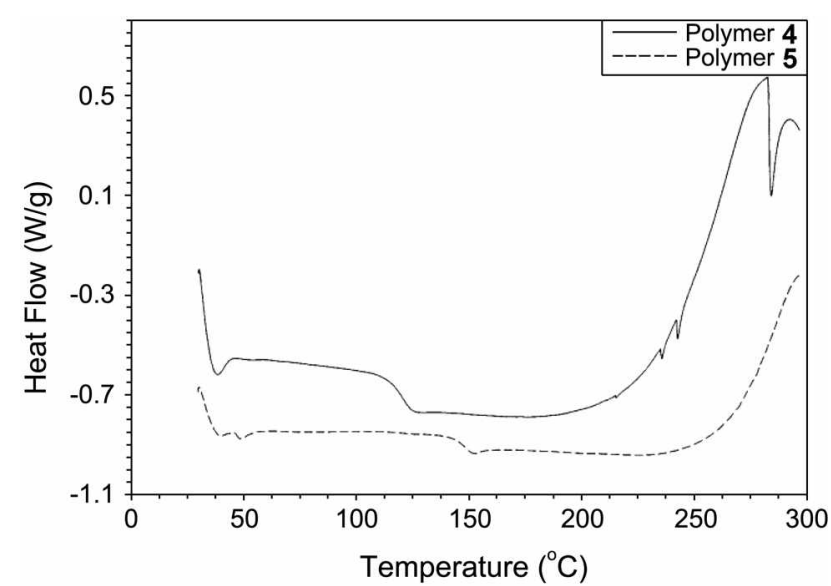

Figure 3. DSC thernograms of polymers 4 and 5 at a heating rate of $10^{\circ} \mathrm{C} / \mathrm{min}$ under nitrogen.

centrosynmetric polar order. the spin-coated polymer films were corona-poled. As the temperature was raised gradually to $5-10{ }^{\circ} \mathrm{C}$ higher than $T_{\mathrm{g}} .6 .5 \mathrm{kV}$ of corona voltage was applied and kept that temperature for $30 \mathrm{~min}$. The poling was confimed by UV-vis spectrum. Polymers 4 and 5 showed strong absorption near $408 \mathrm{~nm}$ by the NLO-chromophore 2.5-dioxybenzylidenemalononitrile group. The UV-vis absorption spectra of the polymer sample 4 before and after poling are presented in Figure 4. After electric poling. the dipole moments of the NLO-chromophores were aligned and UV-vis spectra of polymer 4 exhibited a slight blue shift and a decrease in absorption due to birefringence. From the absorbance change. the order parameter of the poled film could be estimated. which is related to the poling efficiency. The estimated order parameter value $\mathrm{F}$ was equal to 0.29 for polymer $4\left(\Phi=1-A_{1} / A_{i j}\right.$, where $A_{i j}$ and $A_{1}$ are the absorbances of the polymer film before and after poling. respectively). The decrease in absorbance after poling was an indicator of the dipole alignment. For the purpose of investigating surface morphology of polymer films. domain structures of NLO-chromophores for the thin-film samples were obtained with atomic force microscopy (AFM). Figure 5 shows AFM scans of the spin-coated film before and after
Table 2. Themal Properties of Polymers 4 and 5

\begin{tabular}{|c|c|c|c|c|c|c|}
\hline \multirow[b]{2}{*}{ Polymer } & \multirow{2}{*}{$\begin{array}{c}T_{\mathrm{g}}^{a} \\
\left({ }^{\circ} \mathrm{C}\right)\end{array}$} & \multicolumn{4}{|c|}{ Degradation temperature $\left({ }^{\circ} \mathrm{C}\right)^{4}$} & \multirow{2}{*}{$\begin{array}{c}\text { Residule at } \\
800^{\circ} \mathrm{C} \\
(\%)^{4}\end{array}$} \\
\hline & & $\begin{array}{c}\text { Initial- } \\
\text { loss }\end{array}$ & $5 \%$-loss & $20 \%$-loss & $40 \% \operatorname{loss}$ & \\
\hline 4 & 119 & 260 & 281 & 306 & 402 & 40.2 \\
\hline 5 & 146 & 294 & 305 & 348 & 375 & 23.7 \\
\hline
\end{tabular}

${ }^{2}$ Determined from DSC curves measured on a TA 2920 differential scanning calorimeter with a heating rate of $10{ }^{\circ} \mathrm{C}$ min under nitrogen atmospliere. "Determined from TGA curves measured on a DuPont 951 thermogravimetric analyer with a heating rate of $10^{\circ} \mathrm{Cmin}$ under nitrogen atmosphere.

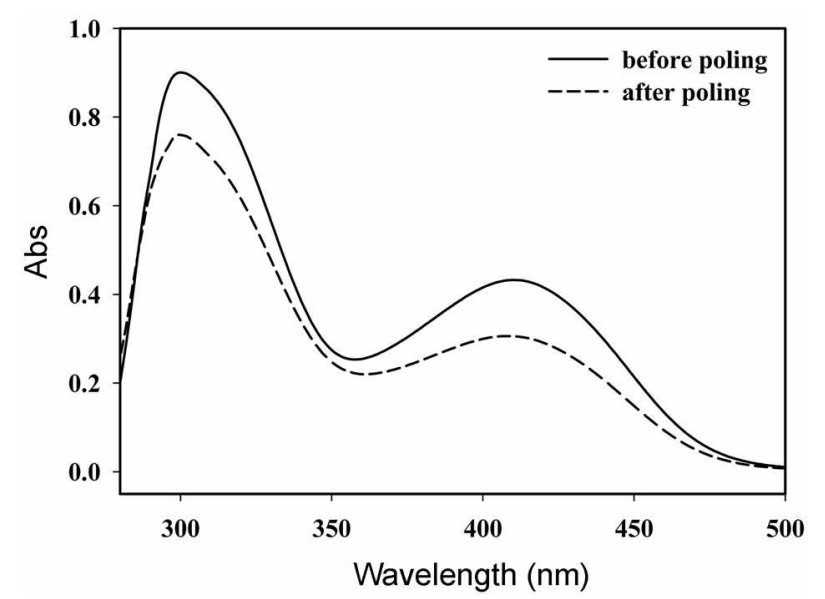

Figure 4 . UV-Vis absorption spectra of a tilm of polymer 4 betore and after poling.

(a)

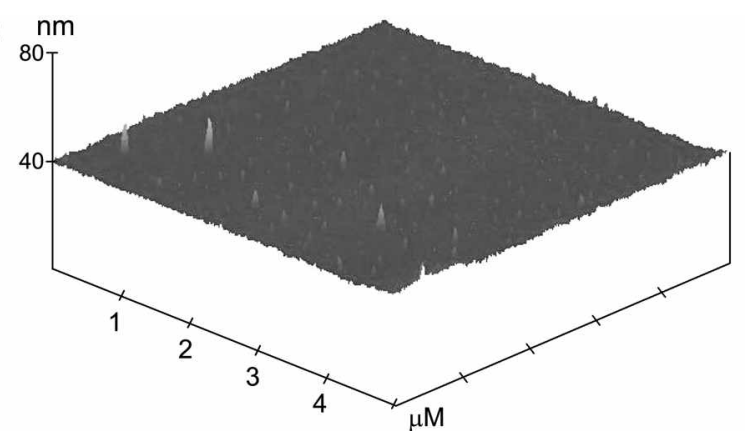

(b)

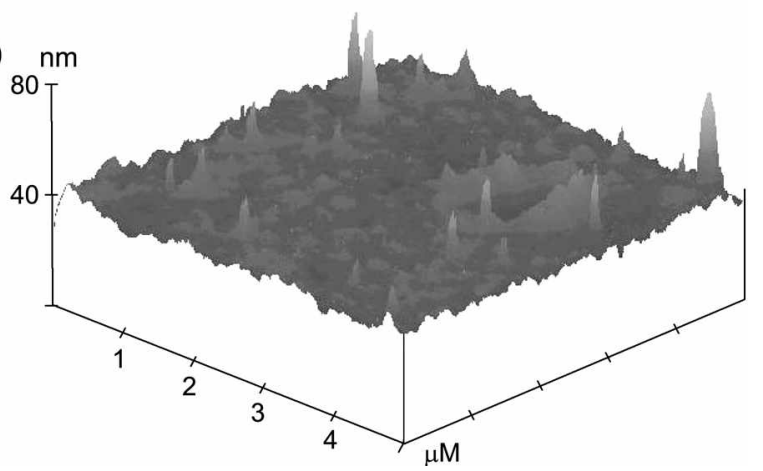

Figure 5. AFM inages of spirt-coated fillm of polymer 4 : (a) betore corona-poling; (b) after corona-poling.

poling for polymer 4 . AFM images show that the surface of the film sample is extremely flat and smooth. However, this good quality film was dramatically changed after poling. 
Table 3. Nonlinear Optical Properties of Polymers 4 and 5

\begin{tabular}{|c|c|c|c|c|c|c|}
\hline Polymer & $\lambda_{\max }{ }^{a}(11712)$ & $d_{33^{0}}$ (esu) & $\Phi^{i}$ & film thickness $(\mu \mathrm{m})$ & $d_{31}^{b}(\mathrm{esu})$ & $n$ \\
\hline 4 & 408 & $(5.82 \pm 0.36) \times 10^{-9}$ & 0.29 & 0.53 & $(2.36 \pm 0.16) \times 10^{-9}$ & $\begin{array}{l}\mathrm{n}_{1}=1.57 \\
\mathrm{n}_{2}=1.65\end{array}$ \\
\hline 5 & 407 & $(5.59 \pm 0.28) \times 10^{-9}$ & 0.14 & 0.51 & $(2.28 \pm 0.16) \times 10^{-9}$ & $\begin{array}{l}\mathrm{n}_{1}=1.58 \\
\mathrm{n}_{2}=1.64\end{array}$ \\
\hline
\end{tabular}

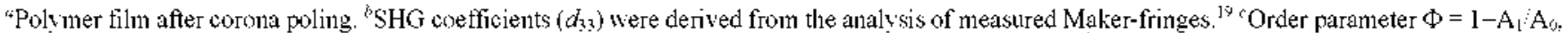
where $A_{n}$ and $A_{1}$ are the absorbances of the polymer film before and after corona poling, respectively: "Film thickness was determined by the optical transmission technique. ${ }^{18}$

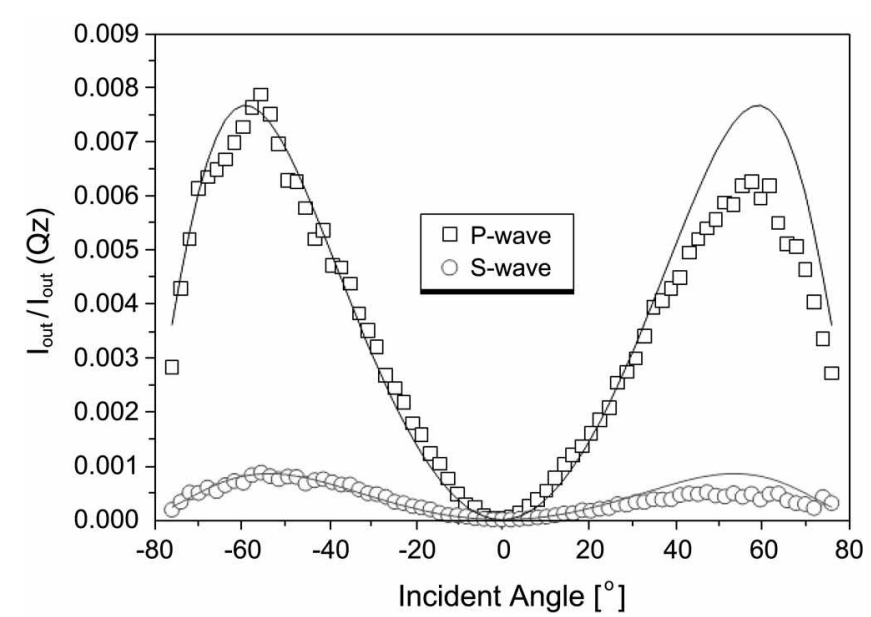

Figure 6. Angular dependence of SHG signal in a poled film of polymer 5 .

resulting in numerous hills and valleys in the surface structure, which means that the NLO-chromophores were aligned in the poling direction, as shown in Figure 5(b).

Nonlinear Optical Properties of the Polymers. The NLO properties were studied by the SHG method. SHG measurements were performed at a fundamental wavelength of $1064 \mathrm{~nm}$ using a mode locked Nd-YAG laser. The refractive index of the sample was measured by the optical transmission technique. ${ }^{\text {Is }}$ The transmittance of thin film includes infommation on the thickness. refractive index and its extinction coefficient. Thus. we could determine these parameters by analyzing the transmittance. In order to determine the microscopic second-order susceptibility of the polymer. the angular SHG dependence was recorded and compared with the values obtained from Y-cut quartz plate. Figure 6 shows the angular dependence of SHG signal in a poled polymer $\mathbf{5}$. The measurements were taken after the poled film was stand at room temperature for 2 days to remove the residue charge by the poling electric field. For the calculation of the $d_{31}$ and $d_{3 \hat{j}}$ values, both $s$-polarized and $\rho$-polarized IR laser were directed to the samples and recorded. The SHG coefficient $d_{3 j}$ was calculated through the method developed by Herman and Hyden. ${ }^{19}$ Nonlinear optical properties of polymers $\mathbf{4}$ and $\mathbf{5}$ are summarized in Table 3. SHG coefficients $\left(d_{33}\right)$ were derived from the analysis of measured Maker-fringes with the Pascal fitting program according to the literature procedure ${ }^{2(1}$ The values of $d_{31}$ and $d_{3 j}$ for polymer 4 were $2.36 \times 10^{-9}$ and $5.82 \times 10^{-9}$ esu. respectively. As expected, these $d_{31}$ and $d_{33}$ values are larger than those of the polyurethanes with 2,5-dioxybenz-

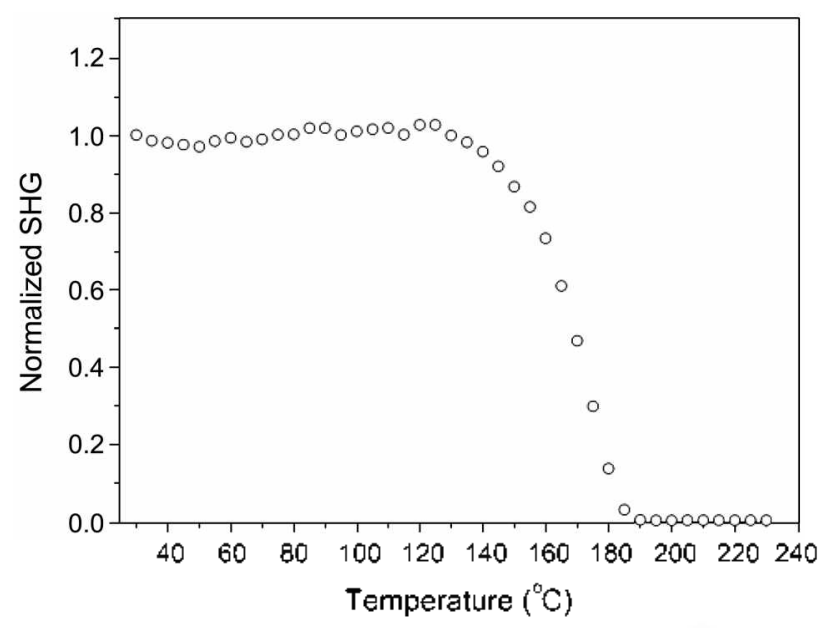

Figure 7. Nomalized SHG signal of polymer 5 as a function of temperature at a heating rate of $10^{\circ} \mathrm{C} / \mathrm{min}$.

ylidenecyanoacetate as a NLO cluromophore. ${ }^{17}$ Because the second hannonic wavelength was at $532 \mathrm{~nm}$. which was not in the absorptive region of the resulting polyurethane, there was not resonant contribution to this $d_{33}$ value. In the isotropic model, the ratio of $d_{33} / d_{31}$ is predicted to be about 3. Our $d_{33} / d_{31}$ value of around 2.5 is in good agreement with the predicted value.

To evaluate the ligh-temperature stability of the polymers, we studied the temporal stability of the SHG signal. In Figure 7 we present the dýnamic thermal stability study of the NLO activity of the film $\mathbf{5}$. To investigate the real-time NLO decay of the SHG signal of the poled polymer films as a function of temperature. in situ SHG measurements were performed at a heating rate of $10^{\circ} \mathrm{C} / \mathrm{mm}$ from $30^{\circ} \mathrm{C}$ to 250 'C. The polymer films + and $\mathbf{5}$ exhibited greater thermal stability and no significant $\mathrm{SHG}$ decay was observed below $140^{\circ} \mathrm{C}$. In general. side chain NLO polymers loose themnal stability below $T_{g}$. The stabilization of the dipole aligmment is a characteristic of main-chain NLO polymers. The high themal stability of second hamonic generation of polymers 4 and 5 was due to the stabilization of dipole alignment of NLO chromophore. which stemmed from the partial main chain character of the polymer structure. Thus, we obtained a new type of NLO polyurethane having the advantages of both main-chain and side-chain NLO polymers: stabilization of dipole alignment and good solubilițy.

\section{Conclusions}

Novel T-type polyurethanes 4 and $\boldsymbol{5}$ with pendant NLO 
chromophores as part of the polymer main chains were synthesized. These mid-type NLO polyurethanes are soluble in common organic solvents and polymers $t$ and 5 displayed a thermal stability up to $250^{\circ} \mathrm{C}$ and $T_{g}$ values in the range 119-146 ${ }^{\circ} \mathrm{C}$. The SHG coefficient $\left(d_{33}\right)$ of corona-poled polymer film was $5.82 \times 10^{-9}$ esu. The striking feature of these polymers is that they exhibit SHG stability up to $T_{g}$ and no significant SHG decay was observed below $140^{\circ} \mathrm{C}$. The high thermal stability of optical nonlinearity stems from the stabilization of dipole alignment of the NLO-chromophore.

\section{Experimental Section}

Materials. The reagent-grade chemicals were purchased from Aldrich and purified by either distillation or recrystallization before use. 2-Chloroetlyl vinyl ether and 2,5dilyydroxybenzaldehyde were used as received. 2.4-Toluenedissocyanate (TDD) was purified by distillation under reduced pressure. 3,3'-Dimethoxy-4,4'-bipheny lenediisocyanate (DMBPI) was recrystallized from ethyl acetate. Piperidine was dried with calciun hydride and fractionally distilled. $N, N$-Dimethylformanide (DMF) was purified by drying with anhydrous calcium sulfate. followed by distillation under reduced pressure.

Measurements. IR spectra were taken on a Shimadzu FT IR-8201PC infrared spectrophotometer. ${ }^{1} \mathrm{H}$ NMR spectra were obtained on a Varian $300 \mathrm{MHz}$ NMR spectrometer. UV-Vis absorption spectra were measured on a Shimiadzu UV-3100S spectrophotometer. Elemental analyses were performed using a Perkin-Elmer $2400 \mathrm{CHN}$ elemental analyzer. The glass transition temperatures $\left(T_{\mathrm{g}}\right)$ were measured on a TA 2920 differential scauning calorimeter in a nitrogen atmosphere. DuPont 951 thermogravinetric analyzer with a heating rate of $10{ }^{\circ} \mathrm{C} / \mathrm{min}$ up to $800^{\circ} \mathrm{C}$ was used for the thermal degradation study of polymers under nitrogen. The number average molecular weight $\left(M_{n}\right)$ and weight average molecular weight $\left(M_{\mathrm{W}}\right)$ of the polymers were estimated by gel permeation chromatography (GPC) (columns styragel HR5E4E: solvent THF). Atomic force microscopy (AFM) images were recorded with a Park Science Instrument Autoprobe $\mathrm{CP}$. operated in a contact mode. which measures topography. Melting points were measured in Buchi 530 melting point apparatus and are corrected. Viscosity values were obtained by using a Cannon-Fenske viscometer

Film Preparation and SHG Measurement. The polymer film was prepared from a $10 \mathrm{wt} \%$ by weight polymer solution in DMF deposited on an indium-tin oxide (ITO) covered glass. Prior to film casting. the polymer solution was filtered through $0.45 \mu \mathrm{m}$ Teflor ${ }^{\text {is }}$ membrane filter. The film was spin cast at room temperature in the range 1000-1200 rpm. The films were dried for $12 \mathrm{~h}$ under vacuum at $60^{\circ} \mathrm{C}$. The alignment of the NLO-chromophore of the polymers was carried out by corona poling method. The poling was performed in a wire-to plane geometry under in situ conditions. The discharging wire to plane distance was $10 \mathrm{~mm}$. As the temperature was raised gradually to $5-10^{\circ} \mathrm{C}$ higher than
$T_{8} .6 .5 \mathrm{kV}$ of corona voltage was applied and kept that temperature for $30 \mathrm{~min}$. The films were cooled to room temperature in the presence of the electric field. Finally. the electric field was removed. The refractive index of the sample was measured by the optical transmission technique. ${ }^{18}$ Second hamonic generation measurement was carried out one day after poling. A continuum PY61 modelocked Nd:YAG laser $(\lambda=1064 \mathrm{~mm})$ with pulse width of 40 ps and repetition rate of $10 \mathrm{~Hz}$ was used as the fundamental light source and $\mathrm{Y}$-cut quartz was used as reference. $\mathrm{A}$ beam splitter and a photodiode were used to compensate for the intensity fluctuations of the fundamental beam $(1064 \mathrm{~lm})$. The polarity of the fundamental laser beam was adjusted using a half-wave plate before it hit the sample. The electric field vector of the incident beam was either parallel ( $p$ polarization) or perpendicular ( $s$-polarization) to the plane of incidence. Only the $p$-polarized SH beam was made to enter a photomultiplier tube (PMT) by using a prism and a $\mathrm{SH}$ pass filter. An analyzer was used to confim the polarization direction of the SH signal. A poled polymer film was mounted on the rotator coupled to a step motor. The output signals from the photodiode and PMT were detected as a function of the incident angle. A 3-mm-thick Y-cut quartz crystal (a piece of quartz plate whose plane is perpendicular to the crystalline $y$-axis and the thichness of the plate is $3 \mathrm{~mm}$. and $\mathrm{d}_{11}=0.3 \mathrm{pm} / \mathrm{V}$ ) was used as a reference for determining the relative intensities of the $\mathrm{SH}$ signals generated from the samples. The Maker Fringe pattem was obtained by measuring the SHG signal at $0.5^{\circ}$ intervals using a rotation stage. SHG coefficients $\left(d_{33}\right)$ were derived from the analysis of measured Maker-fringes. ${ }^{19}$

2,5-Di-(2'-vinyloxyethoxy)benzaldehyde (1). 2,5-Dihydroxybenzaldehyde $(13.8 \mathrm{~g}, 0.10 \mathrm{~mol})$. anhydrous potassium carbonate $(82.9 \mathrm{~g} .0 .60 \mathrm{~mol})$, and 2-chloroetlyl vinyl ether $(16.0 \mathrm{~g}, 0.25 \mathrm{~mol})$ were dissolved in $400 \mathrm{~mL}$ of dry DMF under nitrogen. The mixture was refluxed in an oil bath kept at $80^{\circ} \mathrm{C}$ for $15 \mathrm{~h}$ under nitrogen. The resulting solution was cooled to room temperature. diluted with 300 $\mathrm{mL}$ of water. and extracted with $300 \mathrm{~mL}$ of diethyl ether three times. The organic layer was washed with saturated aqueous sodium chloride solution, and dried with anhydrous magnesium sulfate. Rotary evaporation of diethỵl ether gave crude product. which was recrystallized from 1-butanol yielded $24.5 \mathrm{~g}$ ( $88 \%$ yield) of pure product $1 .{ }^{1} \mathrm{H}$ NMR $\left(\mathrm{CDCl}_{3}\right) \delta 3.98-4.34$ (m. $12 \mathrm{H}, 2 \mathrm{CH}_{2}=.2-\mathrm{O}-\mathrm{CH}_{2}-\mathrm{CH}_{2}-\mathrm{O}-$ ), 6.45-6.58 (m. 2H. 2 =CH-O-). 6.92-6.99 (m. lH. aromatic), 7.15-7.21 (m. $1 \mathrm{H}$. aromatic). 7.33-7.36 (d. $1 \mathrm{H}$. aromatic). 10.46 (s. $1 \mathrm{H}$. -CHO). IR $(\mathrm{KBr}) 3096.3075(\mathrm{w}=\mathrm{C}-\mathrm{H}) .2941$. 2882 (s. C-H). 1676 (vs. C=O), 1624 (vs. $\mathrm{C}=\mathrm{C}$ ) $\mathrm{cm}^{-1}$.

2,5-Di-(2'-vinyloxyethoxy)benzylidenemalononitrile (2). Piperidine $(0.13 \mathrm{~g} .1 .5 \mathrm{mmol})$ was added to a solution of 2.5 di-(2'-vinyloxyethoxy)benzaldehy'de 1 ( 8.35 g. $30 \mathrm{mmol})$ and malononitrile $(2.18 \mathrm{~g} .33 \mathrm{mmol})$ in $170 \mathrm{~mL}$ of l-butanol with stirring at $0^{\circ} \mathrm{C}$ under nitrogen. After stirring for $4 \mathrm{~h}$ at 0 ${ }^{\circ} \mathrm{C}$. the reaction mixture was cooled to $-10^{\circ} \mathrm{C}$ for crystallization. The product was filtered and washed successively with cold l-butanol $(80 \mathrm{~mL})$, water $(30 \mathrm{~mL})$, and cold $\mathrm{l}$ - 
butanol $(20 \mathrm{~mL})$. The obtained pale yellow product was recrystallized from l-butanol to give $8.61 \mathrm{~g}$ ( $88 \%$ yield) of 2 . $\mathrm{Mp}=72.74{ }^{\circ} \mathrm{C} .{ }^{1} \mathrm{H}$ NMR $\left(\mathrm{CDCl}_{3}\right) \delta 4.02+4.40(\mathrm{~m} .12 \mathrm{H}, 2$ $\left.\mathrm{CH}_{2}=.2-\mathrm{O}-\mathrm{CH}_{2}-\mathrm{CH}_{2}-\mathrm{O}-\right) .6 .46-6.58(\mathrm{~m}, 2 \mathrm{H} .2=\mathrm{CH}-\mathrm{O}-)$ 6.94-6.98 (d, IH. aromatic), 7.18-7.23 (q, IH. aromatic). $7.75-7.78$ (d. IH. aronatic), 8.31 (s. $1 \mathrm{H}, \mathrm{Ph}-\mathrm{CH}=$ ). IR (KBr) $3057(\mathrm{w},=\mathrm{C}-\mathrm{H}), 2941.2885$ (m, C-H), 2222 (s. CN), 1624. 1578 (vs. $\mathrm{C}=\mathrm{C}$ ) $\mathrm{cm}^{-1}$. Anal. Calcd for $\mathrm{C}_{18} \mathrm{H}_{18} \mathrm{~N}_{2} \mathrm{O}_{4}$ : C. 66.25 : H. 5.56: N, 8.58. Found: C, 66.36: H. 5.64: N, 8.50.

2,5-Di-(2'-hydroxyethoxy)benzylidenemalononitrile (3). Aqueous hydrochloric acid $(1.5 \mathrm{M}, 30 \mathrm{~mL})$ was slowly added to a solution of 2,5-di-(2'-viny loxyethoxy)benzylidenemalononitrile (2) $(8.48 \mathrm{~g} .0 .026 \mathrm{~mol})$ in $60 \mathrm{~mL}$ of $\mathrm{dry}$ THF with stirring under nitrogen at $0^{\circ} \mathrm{C}$. The misture was stirred at $80^{\circ} \mathrm{C}$ for $8 \mathrm{~h}$ under nitrogen. The resulting solution was extracted with diethyl ether $(80 \mathrm{~mL})$ three times. The organic layer was washed successively with saturated sodium chloride. sodium hydrogen carbonate, and water. followed by drying with anhydrous magnesium sulfate. Rotary evaporation of diethyl ether gave crude product. The obtained pale yellow product was recrystallized from ethyl acetate to give $6.06 \mathrm{~g}(85 \%$ yield $)$ of $3 . \mathrm{Mp}=138-140{ }^{\circ} \mathrm{C} .{ }^{1} \mathrm{H}$ NMR (acetone- $d_{6}$ ) $83.74-3.94\left(\mathrm{~m} .+\mathrm{H} .2-\mathrm{CH}_{2}-\mathrm{OH}\right), 3.94-4.12$ (m. $2 \mathrm{H},-\mathrm{OH}), 4.12-4.22\left(\mathrm{~m}, 4 \mathrm{H} .2-\mathrm{O}-\mathrm{CH}_{2}\right), 7.15-7.32(\mathrm{~m}, 2 \mathrm{H}$. aromatic) .7 .75 (s. $1 \mathrm{H}$. aromatic). $8.58(\mathrm{~s}, 1 \mathrm{H} .-\mathrm{Ph}-\mathrm{CH}=$ ). IR (KBr) 3516.3233 (s, O-H). 3045 (m, =C-H). 2941 (m, C-H). 2233 (m, CN), 1576 (s. C=C) $\mathrm{cm}^{-1}$. Anal. Calcd for $\mathrm{C}_{14} \mathrm{H}_{4} \mathrm{~N}_{2} \mathrm{O}_{4}: \mathrm{C}, 61.31 ; \mathrm{H}, 5.14:$ N. 10.21. Found: C. 61.41: H. 5.22: N, 10.28 .

Synthesis of polyurethanes + and 5 . A representative polyaddition reaction procedure (the case of 4 ) was as follows: $2.4-T o l u e n e d i i s o c y a n a t e ~(1.74 \mathrm{~g} .0 .01 \mathrm{~mol})$ was added slowly to a solution of $2.74 \mathrm{~g}$ of diol $3(0.01 \mathrm{~mol})$ in $25 \mathrm{~mL}$ of anhydrous DMF. The resulting solution was degassed by a freeze-thaw process under vacuum and placed in an oil bath kept at $80^{\circ} \mathrm{C}$. After heating $10 \mathrm{~h}$ with stirring the polymerization tube was opened and the viscous polymer solution was poured into $400 \mathrm{~mL}$ of cold water. The precipitated polymer was collected and reprecipitated from DMSO into methanol. The polymer was further purified by extraction in a Soxhlet extractor with diethyl ether and dried under vacuum to give $4.13 \mathrm{~g}$ (92\% yield) of polymer 4 : $\eta_{\text {inh }}=0.30 \mathrm{dL} \mathrm{g}^{-1}$ (c, $0.5 \mathrm{~g} \mathrm{dL}^{-1}$ in DMSO at $\left.25^{\circ} \mathrm{C}\right)$. ${ }^{1} \mathrm{H} \mathrm{NMR}$ (DMSO- $\left.d_{6}\right) \delta 2.07\left(\mathrm{~s}, 3 \mathrm{H},-\mathrm{CH}_{3}\right), 4.14-4.47(\mathrm{t}, 8 \mathrm{H}, 2-\mathrm{O}-$ $\mathrm{CH}_{2}-\mathrm{CH}_{2}-\mathrm{O}-$ ). 6.92-7.59 (m, 6H, aromatic), 8.40-8.45 (d, 1H. $\mathrm{Ph}-\mathrm{CH}=$ ), 8.92-8.98 (d. 1H. N-H). 9.63-9.72 (d. IH. NH). IR (KBr) 3337 (s. N-H). 2953 (m. C-H). 2222 (m. CN).
1722 (vs, C=O). 1595 (s. C=C) $\mathrm{cm}^{-1}$. Anal. Calcd for $\left(\mathrm{C}_{23} \mathrm{H}_{20} \mathrm{~N}_{4} \mathrm{O}_{6}\right)_{n}: \mathrm{C}$. 61.60: H, 4.50: N. 12.49. Found: $\mathrm{C}$. 61.68; H. 4.59: N. 12.58. Polymer 5: $\eta_{\text {unh }}=0.29 \mathrm{dL} \mathrm{g}^{-1}$ (c, 0.5 $\mathrm{g} \mathrm{dL}^{-1}$ in DMSO at $25^{\circ} \mathrm{C}$ ). ${ }^{i} \mathrm{H}$ NMR (DMSO- $\left.d_{0}\right) \delta 3.88(\mathrm{~s}$ $\left.6 \mathrm{H} .2-\mathrm{OCH}_{3}\right), 4.17-4.53\left(\mathrm{q}, 8 \mathrm{H}, 2-\mathrm{O}-\mathrm{CH}_{2}-\mathrm{CH}_{2}-\mathrm{O}-\right)$. 7.167.39 (d. $6 \mathrm{H}$, aromatic), $7.57-7.76$ (d. $2 \mathrm{H}$, aromatic). 8.20 (d, IH. aromatic), 8.47 (s. $1 \mathrm{H}$, aromatic). $8.59-8.66$ (d, $1 \mathrm{H}, \mathrm{N}-$ H), 9.02 (s, lH. N-H). IR (KBr) 3420 (m. N-H). 2941 (m. C$\mathrm{H}), 2233(\mathrm{~m}, \mathrm{CN}) .1728(\mathrm{~s}, \mathrm{C}=\mathrm{O}), 1583(\mathrm{~s}, \mathrm{C}=\mathrm{C}) \mathrm{cm}^{-1}$. Anal. Calcd for $\left(\mathrm{C}_{30} \mathrm{H}_{2} \mathrm{~N}_{4} \mathrm{O}_{5}\right)_{37}: \mathrm{C}, 63.15 ; \mathrm{H} .4 .59 ;$ N. 9.82. Found: C, 63.25: H, 4.64; N, 9.88.

Acknowledgements. This work was supported by the Korea Research Foundation Grant funded by the Korean Government (MOEHRD. Basic Research Promotion Fund) (KRF-2007-313-C00498).

\section{References}

1. Cho. M. J.: Kim, J. Y.: Kim, J. H.; Lee, S. H.; Dalton, L. R.: Choi. D. H. Bull. Konan Chem. Soc. 2005. 26.77.

2. Lee. C. Park, S.-K; Yang M.; Lee, N.-S; Kim. N. J. Bull. Korem Chem. Soc. 2007. 28. 447.

3. Hant. K. S.: Park. S. K.: Shim. S. Y.: Tahn1g. W. S.: Kim. N. T. Bull. Korean Chem. Soc. 1998. 19.1165.

4. Han. K. S.; Park, S. K.: Shim. S. Y; Lee, Y. S.: Jahng. W. S.: Kim. N. J. Bull. Korean Chem. Soc. 1998.19 .1168$.

5. Cho. B. R.: Kim. Y. H.: Son. K. W.: Khalil, C: Kim, Y. H; Jeon. S.-T. Bull. Korem Chent Soc. 2002. 23. 1253.

6. Moonl. J. R.: Kiml. B. S.: Kim. J-H. Bull Korean Chent Soe 2006. 27. 981

7. Kim. M. H.: Jin. J.-I: Lee, C. J.: Kim. N. J.: Park, C. H. Bull. Korean Chem. Soc. 2002. 23, 964.

8. Tsutsumi, N.: Morishima. M; Sakai. W. Hacromolecules 1998 31.7764 .

9. Moon. K. J.: Shim. H. K.: Lee. K. S.: Zieba. T.: Prasad. P. N Macrontolecules 1996. 29.861.

10. Woo, H. Y.: Lee, K. S.; Shim, H. K. Polym J. 2000, 32,8

11. Tsutumi, N.: Matsumoto, O.; Sakai. W.; Kiyotsukuri, T. Hacmmolecules 1996. 29, 592

12. Tsutumi. N.: Matsumoto. O.: Sakai. W. Macronolecules 1997. 30. 4584.

13. Lee. T.-Y: Park. E.-T, J. Pohn. Sci. Part A: Polmm. Chem. 2002. 40. 1742 .

14. Lee. J.-Y.: Park. E.-J.; Lee. H.: Rhee, B. K. Polym. Bull. 2002, 48. 233.

15. Lee. J.-Y: Bang. H.-B.: Park. E--T.: Baek. C. S.: Rhee. B. K.: Lee. S. M. Sw. Met. 2004. 1H4. 159

16. Lee. T.-Y.: Bang. H.-B.: Kang. T.-S.: Park. E.-J. Europ. Polm. J. 2004. 40,1815

17. Lee. J.-Y.: Bang. H.-B.: Baek. C. S. Sy. 1fet. 2005, 148, 161 .

18. Cisneros, J. I. Appl. Opt. 1998. 37. 5262.

19. Herman. W. N.: Hayden. L. M. J. Opt. Soc. Ant. B 1995. 12. 416. 